\title{
EVALUATE THE EFFECTIVENESS OF WORKPLACE PHYSICAL EXRECISE PROGRAMME ON MUSCULOSKELETAL PAIN AND FUNCTIONAL LIMITATION AMONG SEDENTARY OFFICE WORKERS
}

Dr. Vinoli. S. G*

*Professor, Universal College Of Nursing, Bangalore, Karnataka, India.

DOI: http://doi.org/10.47211/idcij.2020.v07iws02.010

\section{ABSTRACT}

Computer based customer service work is one of the most rapidly growing occupations in the world. In the coming years, postural or musculoskeletal problems will be common to many sedentary job employees. To evaluate the effectiveness of workplace physical exercise programme on musculoskeletal pain and functional limitations among the sedentary office workers, a True experimental pre-test post-test design with control group was adopted. 200 sedentary office workers were selected by simple random sampling method. Pre-test was done by using self-administered questionnaire. After the pre-test teaching and demonstration was given to the experimental group. Once in every 15 days the samples were supervised for their performance. Totally six observations were made for each sample throughout the study. After completion of six observations the posttest was conducted. The results showed that there was a significant difference between the pre-test and posttest mean musculoskeletal pain score $(t=40.168, P=0.000)$ in the experimental group. There was a significant difference in the post-test mean musculoskeletal pain score between the experimental and control group $(t=13.738, P=0.000)$. It also exhibits that there was a significant difference between the pre-test and post-test mean functional limitations score $(t=30.709, P=0.000)$ in the experimental group. There was a significant difference in the post-test mean functional limitations score between the experimental and the control group $(t=18.3, P=0.000)$. There was a highly significant relationship between musculoskeletal pain and functional limitations in both the experimental group and the control group during pre-test and post-test. So it was inferred that workplace physical exercise programme was highly effective in reducing work related musculoskeletal pain and improve the functional abilities.

Key Words: Sedentary office workers, musculoskeletal pain and functional limitations.

\section{ABOUT AUTHOR:}

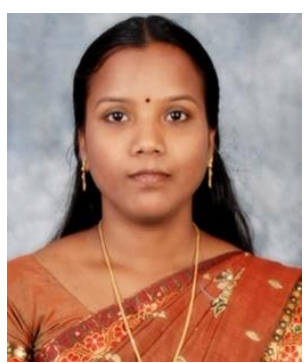

Author Dr. Vinoli. S. G is Professor at Universal College of Nursing, Bangalore, Karnataka, India. 


\section{BACKGRTOUND OF THE STUDY}

Among the working people between 18 to 64 years of age, the disorders of the muscular and skeletal systems rank the first among the factors that cause functional limitations and restrictions. Computer based customer service work or call centre work is one of the most rapidly growing occupations in the world. Musculoskeletal disorders of the upper extremities and neck are the most common occupational health problems associated with this type of work. According to the World Health Organization (WHO) a sedentary lifestyle is one of the top ten causes of morbidity and mortality worldwide. WHO claimed that effective public health measures were urgently required to promote physical activity and improve public health worldwide. Researchers indicate musculoskeletal symptoms are more frequently reported by computer operators than workers in traditional jobs.

An average office worker spends about 80,000 hours seated in the course of his working life and $80 \%$ of those who work at the computer every day regularly suffer from health problems. Two thirds suffer from tension and pain in the shoulder and neck, more than half have back problems and around $45 \%$ suffer from eye problems and headaches.

\section{STATEMENT OF THE PROBLEM}

"An experimental study to evaluate the effectiveness of workplace physical exercise programme on musculoskeletal pain and functional limitation among the sedentary office workers in selected settings of Kanyakumari District".

\section{OBJECTIVES OF THE STUDY}

$\square$ To assess the level of musculoskeletal pain among sedentary office workers before and after implementing workplace physical exercise programme.

$\square$ To assess the level of functional limitation among sedentary office workers before and after implementing workplace physical exercise programme.

$\square$ To evaluate the effectiveness of workplace physical exercise programme on musculoskeletal pain among sedentary office workers.

$\square$ To evaluate the effectiveness of workplace physical exercise programme on functional limitation among sedentary office workers.

$\square$ To find out the relationship between the musculoskeletal pain and functional limitation among sedentary office workers.

$\square$ To find out the association between the pre-test level of musculoskeletal pain of sedentary office workers and their selected socio-demographic variables.

$\square$ To find out the association between the pre-test level of functional limitation of sedentary office workers and their selected socio-demographic variables.

\section{HYPOTHESIS}

$\mathrm{H}_{1}$ - The mean post-test musculoskeletal pain score of sedentary office workers in the experimental group who underwent the exercise programme will be significantly lower than their mean pre-test score.

$\mathrm{H}_{2}$ - The mean post-test musculoskeletal pain score of sedentary office workers in the experimental group who had the exercise programme will be significantly lower than the mean post-test musculoskeletal pain score of the control group.

$\mathrm{H}_{3}$ - The mean post-test functional limitation score of sedentary office workers in the experimental group who underwent the exercise programme will be significantly lower than their mean pre-test score.

$\mathrm{H}_{4}$ - The mean post-test functional limitation score of sedentary office workers in the experimental group who had the exercise programme will be significantly lower than the mean post-test functional limitation score of the control group.

$\mathrm{H}_{5}$ - There will be a significant relationship between musculoskeletal pain and functional limitation among sedentary office workers.

$\mathrm{H}_{6}$ - There will be significant association between the pre-test level of musculoskeletal pain of sedentary office workers and selected socio-demographic variables.

$\mathrm{H}_{7}$ - There will be significant association between the pre-test level of functional limitation of sedentary office workers and selected socio-demographic variables.

\section{SAMPLING CRITERIA}

\section{Inclusion Criteria}

$\square$ Sedentary office workers working in selected Government and Private Banks, computer centers and post offices.

$\square$ Sedentary office workers having work related neck and shoulder pain.

$\square$ Sedentary office workers in the age group of 25 to 65 years. 


\section{Exclusion Criteria}

$\square$ Sedentary office workers who are not willing to participate in the study.

$\square$ Sedentary office workers having inter-vertebral disc prolapse or any spinal problems.

$\square$ Sedentary office workers having musculoskeletal disorders.

\section{RESEARCH METHODOLOGY}

To accomplish the objectives of the study "True Experimental Pre-test Post-test Design with Control Group" was adopted for the present study. The study was conducted at selected Government and Private Banks, computer centers and post offices after obtaining formal permission from the concerned authorities. Survey was conducted to identify the samples with musculoskeletal pain. Sedentary office workers with work related musculoskeletal pain that fulfilled the inclusion criteria and given informed consent were included in the study. The samples were selected by using Random sampling technique. The tool was prepared by the investigator after an extensive review of literature and discussion with the experts in the field. The tool consists of 4 parts

Section A:

Survey Questionnaire

Section B

Part I: Data pertains to socio-demographic characteristics

Part II: Clinical Variables

Part III: Ergonomic Variables

Section C:

Numerical Pain Rating Scale

Section D: Modified Functional Disability Index Questionnaire

This section was divided into two parts. They are -

$\square$ Modified Croft Disability Questionnaire

Modified Neck Pain Disability Index Questionnaire

The reliability of the tool was computed by using Split half technique, where ' $r$ ' value obtained was showed that the tools were reliable and valid.

\section{METHOD OF DATA COLLECTION}

The data collection was done in four phases

Phase I: Survey was done to identify the samples with musculoskeletal pain.

Phase II: Pre-test was conducted by using a self-administered questionnaire.

Phase III: Physical exercise programme was conducted and instructed to perform it for twice a day, and supervision was carried out to observe their performance for once in 15 days.

Phase IV: Post test was conducted using the same tool after completing six observations for each sample.

\section{RESULTS/ MAJOR FINDINGS}

Data on assessment of musculoskeletal pain

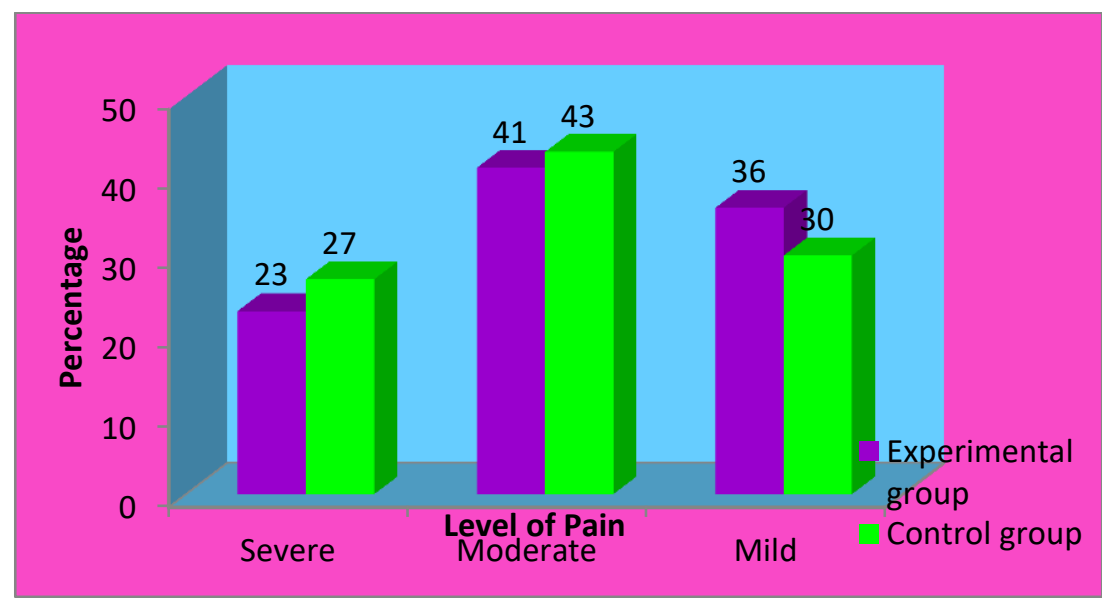

Figure 1: Distribution of samples according to the pre-test level of pain

It reveals that, out of 200 samples $41(41 \%)$ and $43(43 \%)$ had moderate pain in the experimental and the control group, $36(36 \%)$ and $30(30 \%)$ had mild pain in the experimental and the control groups respectively, and least of $23(23 \%)$ and $27(27 \%)$ them had severe pain in the experimental and the control groups. 


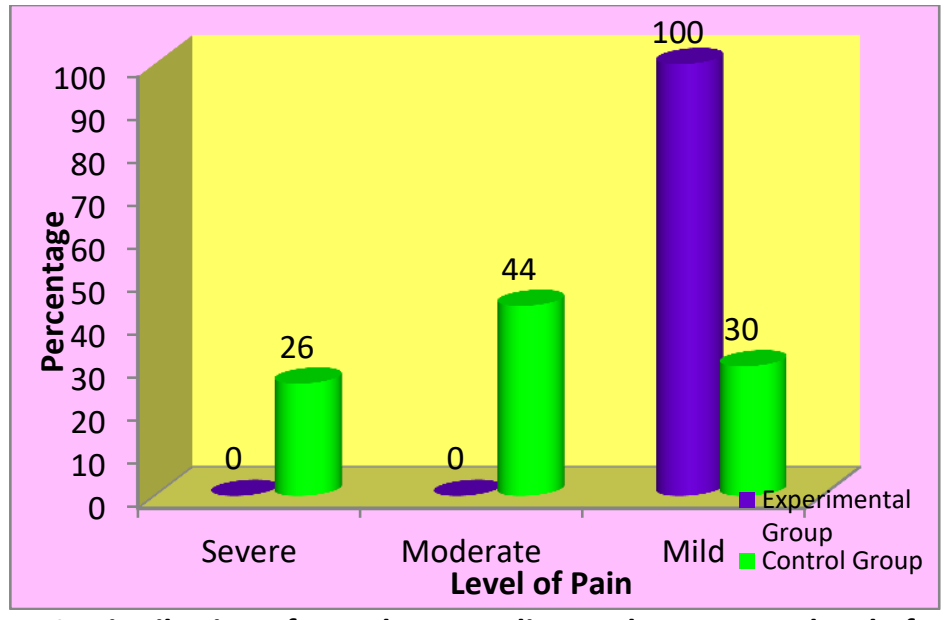

Figure 2: Distribution of samples according to the post-test level of pain.

It reveals that in the experimental group, all of them $100(100 \%)$ had mild pain and in the control group majority of (44\%) them had moderate pain, $30(30 \%)$ had mild pain and only $26(26 \%)$ had severe pain.

Data on assessment of functional limitation

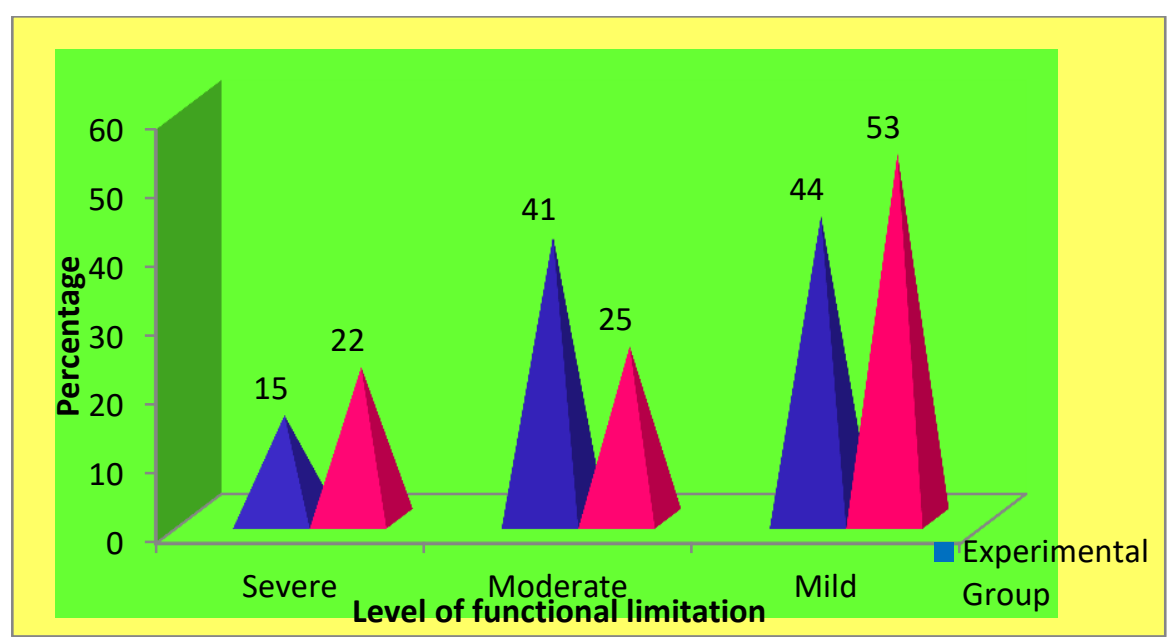

Figure 3: Distribution of samples according to the pre-test level of functional limitation

It reveals that out of 200 samples 44 (44\%) and 53 (53\%) had mild functional limitation, 41 (41\%) and 25 (25\%) had moderate functional limitation and only $15(15 \%)$ and $22(22 \%)$ had severe functional limitation in both, the experimental and the control groups respectively.

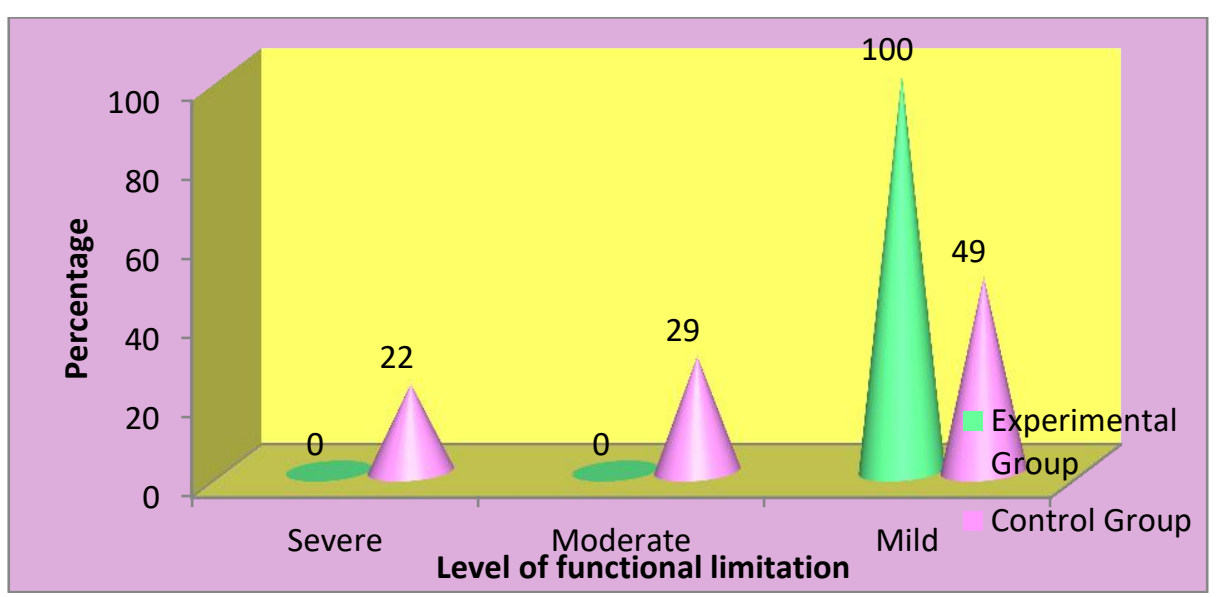

Figure 4: Distribution of samples according to the post-test level of functional limitation

It reveals that in the experimental group, all 100 (100\%) of them had mild functional limitation and in the control group majority of them (49\%) had mild functional limitation, 29 (29\%) had moderate functional limitation and least 22 (22\%) of them had severe functional limitation. 
Data on correlation between musculoskeletal pain and functional limitation

Table 1: Correlation between musculoskeletal pain and functional limitation of sedentary office workers in the experimental group

$\mathrm{N}=\mathbf{1 0 0}$

\begin{tabular}{|c|c|c|c|c|c|c|c|c|}
\hline \multirow[b]{2}{*}{ ASSESSMENT } & \multicolumn{3}{|c|}{ Musculoskeletal pain } & \multicolumn{3}{|c|}{ Functional Limitation } & \multirow{2}{*}{$\begin{array}{l}\text { Karl Pearson } \\
\text { Correlation of } \\
\text { Coefficient }\end{array}$} & \multirow[b]{2}{*}{ P-Value } \\
\hline & Mean & SD & $\%$ & Mean & SD & $\%$ & & \\
\hline PRETEST & 5.06 & 1.791 & 50.6 & 17.08 & 6.56 & 28.47 & $0.902^{*}$ & 0.000 \\
\hline POSTTEST & 1.78 & 1.715 & 17.8 & 3.12 & 2.60 & 7.8 & $0.859^{*}$ & 0.000 \\
\hline
\end{tabular}

*at $\mathbf{0 . 0 5 \%}$ level of significance

Above table shows the significant relationship between musculoskeletal pain and functional limitation in the experimental group during pre-test.

And also shows the significant relationship between musculoskeletal pain and functional limitation in the experimental group during post-test.

Table 2: Correlation between musculoskeletal pain and functional limitation of sedentary office workers in the control group

\begin{tabular}{|c|c|c|c|c|c|c|c|c|}
\hline \multirow[b]{2}{*}{ ASSESSMENT } & \multicolumn{3}{|c|}{ Musculoskeletal pain } & \multicolumn{3}{|c|}{ Functional limitation } & \multirow{2}{*}{$\begin{array}{l}\text { Karl Pearson } \\
\text { Correlation of } \\
\text { Coefficient }\end{array}$} & \multirow[b]{2}{*}{ P-Value } \\
\hline & Mean & SD & $\%$ & Mean & SD & $\%$ & & \\
\hline PRETEST & 4.93 & 1.683 & 49.3 & 16.82 & 7.235 & 28.03 & $0.919^{*}$ & 0.000 \\
\hline POSTTEST & 4.98 & 1.576 & 49.8 & 16.86 & 7.068 & 28.1 & $0.918^{*}$ & 0.000 \\
\hline
\end{tabular}

*at $\mathbf{0 . 0 5 \%}$ level of significance

The above table shows the significant relationship between musculoskeletal pain and functional limitation in the control group during pre-test.

And also it shows the significant relationship between musculoskeletal pain and functional limitation in the control group during post-test.

Data on association between the pre-test level of musculoskeletal pain and selected socio-demographic variables.

There was a significant association between the pre-test level of musculoskeletal pain of sedentary office workers and the selected socio-demographic variables in both, the experimental and the control groups.

Data on association between the pre-test level of functional limitation and selected socio-demographic variables.

There was a significant association between the pre-test level of functional limitation of sedentary office workers and the selected socio-demographic variables in both, the experimental and the control groups.

\section{RECOMMENDATIONS FOR FURTHER STUDY}

Based on the findings of the study, the following recommendations have been made for further study:

$\square$ A similar study can be undertaken on a larger scale for better generalization.

$\square$ Longitudinal study can be conducted for long term effects of physical exercises on the sedentary office workers.

$\square \quad$ A similar study can be conducted on different age group to find out the age impact on the occurrence of musculoskeletal disorders.

\section{CONCLUSION}

Work-related symptoms in neck and shoulder are common among occupational computer users and other sedentary occupations. Additionally, studies have shown that $31 \%$ decrease in quality of life among workers with neck/shoulder symptoms. The study concluded that the musculoskeletal pain was reduced after the physical exercise programme and improved functional ability. Hence it believes that physical exercise programme was proved to be more effective in reducing musculoskeletal pain and improving functional ability. 


\section{REFERENCES}

1. Rempel, D M. et.al. (2006, December). A randomised controlled trial evaluating the effects of two workstation interventions on upper body pain and incident musculoskeletal disorders among computer operators. Occup Environ Med, 63(12), 856.

2. Darrell Wehrend, DC. (2010, September 7). Stretching, breaks and posture important for sedentary office workers. Physicians Sports and Injury Center.

3. Ramakant D. Gaikwad. (2011-12, May-June). Effectiveness of Self Instructional Module on Knowledge regarding prevention of Musculoskeletal Discomfort among Sedentary office workers. Sinhgad eJournal of Nursing, Volume I, Issue I, 24-29. www.nursingteachers.org

4. Bibi Gram. et.al. (2014). Effect of Training Supervision on Effectiveness of Strength Training for Reducing Neck/Shoulder Pain and Headache in Office Workers: Cluster Randomized Controlled Trial. BioMed Research International, 2014, 9. Retrieved from http://dx.doi.org/10.1155/2014/693013

5. Akrouf, QAS. et.al. (2010). Musculoskeletal disorders among bank office workers in Kuwait. Eastern Mediterranean Health Journal, 16, 1, 94-100. 